\title{
UN PERITAJE ANTROPOLÓGICO EN MEMORIA SOCIAL
}

\section{AN ANTHROPOLOGICAL COURT REPORT IN SOCIAL MEMORY}

\author{
Pedro TOMé MarTíN* \\ ILLA-CSIC
}

\begin{abstract}
Resumen: La realización de peritajes jurídicos por parte de antropólogos ha comenzado a ser relativamente frecuente en América Latina en el contexto de juicios relacionados con los pueblos originarios y otros ámbitos de conflicto como los feminicidios. Sin embargo, existe una escasa bibliografía sobre las implicaciones que estos peritajes tienen para la propia disciplina y, especialmente, sobre los dilemas éticos, las repercusiones políticas y los ajustes epistemológicos que plantea esta práctica. El presente texto analiza estos aspectos a partir del proceso de creación del primer informe pericial antropológico sobre las víctimas del franquismo, realizado en Espańa en 2012, en el cual participó el autor de este artículo.
\end{abstract}

Palabras claVe: informe pericial, memoria histórica, ética, antropología social.

AвSTRACT: The realization of expert court reports by anthropologists has begun to be relatively frequent in Latin America in the context of trials related to native peoples and other areas of conflict such as femicides. However, there is a scarce bibliography on the implications that these expert reports have for the discipline itself and, especially, on the ethical dilemmas, the political repercussions and the epistemological adjustments that this practice proposes. This text analyzes these aspects using the process of creating the first anthropological expert report on the victims of Francoism, made in Spain in 2012, in which the author of this article participated.

KeYwords: Expert Court Report, Historical Memory, Ethic, Social Anthropology.

* Instituto de Lengua, Literatura y Antropología, CSIC. pedro.tome@cchs.csic.es 
Desde sus inicios la antropología social y cultural ha ido mudando tanto sus objetos de estudio como sus justificaciones teóricas en función de la multiplicidad de contextos sociales y científicos con los que ha debido dialogar. Dicha variabilidad no ha anulado en ningún momento la pretensión de cientificidad que desde sus inicios tiene la disciplina ${ }^{1}$. No obstante, ha ido mudando la forma en que este propósito se entendía. Por ejemplo, Robert Lowie concluía la conferencia que leyó en la Universidad de Oregon en 1936, afirmando que

la etnología es simplemente una ciencia que se enfrenta a fenómenos que se diferencian del resto del universo por ser "culturales". Es una disciplina totalmente objetiva, aunque trate de actitudes subjetivas o no, ya que su función es la determinación de la realidad en términos verificables. (Lowie 1960: 410)

Esa necesidad de objetividad le llevaría a afirmar en su conocida Historia de la etnología que

El procedimiento científico moderno es el de abstenerse de cualquier juicio subjetivo (...) El antropólogo, como individuo, no puede dejar de responder a manifestaciones de otras culturas, de acuerdo con sus normas individuales y nacionales; pero como hombre de ciencia registra simplemente costumbres como el canibalismo o el infanticidio, comprendiéndolas y, si le es posible, explicándolas. (Lowie 1985: 39)

Algo no muy alejado sugería dos décadas después Radcliffe-Brown. Si bien este consideraba que los resultados que las monografías antropológicas podrían ser de gran utilidad para que misioneros, maestros, magistrados o administradores resolvieran problemas relativos a las creencias o costumbres de los pueblos indígenas, afirmaba que no era tarea de la antropología buscar la solución a los mismos:

la misión del antropólogo social no consiste en buscar la solución de esos problemas prácticos, y me parece que sería imprudente de su parte intentarlo. El científico debe mantenerse lo más libre posible de las consideraciones sobre la aplicación práctica de sus resultados, y con mayor razón en un

1 El primer capítulo de Cultura Primitiva, posiblemente la más conocida e influyente de las obras de E.B. Tylor, publicada en 1871, llevaba el sintomático título de «La Ciencia de la Cultura» (Tylor 1977: 19). 
sector de problemas sobre los cuales se discute con acaloramiento e incluso con prejuicios. Su trabajo consiste en estudiar la vida y las costumbres de los indígenas y encontrar su explicación desde el punto de vista de las leyes generales. (Radcliffe-Brown 1975: 53) ${ }^{2}$

Lejos, no obstante, de la intención de estas páginas presentar una historia de la antropología desde el punto de vista de su relación con la cientificidad. Más bien, las alusiones precedentes pretenden mostrar cuál ha sido el punto de partida de una ciencia que durante la primera mitad del siglo XX «buscaba la objetividad del relato, la memoria más genuina, el punto de vista del nativo, la representación perfecta de una sociedad: un texto etnográfico debía considerar los cánones de la cientificidad» (Franceschi 2019). Sin embargo, entrados ya en el siglo XXI, ese weberiano anhelo de una neutralidad axiológica sería visto como muestra de un positivismo candoroso difícilmente asumible. Cabe recordar, al respecto, que «si se creyera en las representaciones más chatas del precepto weberiano, bastaría precaverse de la parcialidad afectiva e incitaciones ideológicas sobre la significación de los conceptos y la pertinencia de las técnicas» (Bourdieu et al. 2002: 61). Entre aquellos comienzos y nuestros días, la antropología ha pasado por crisis y cambios relevantes. Avanzado el siglo XX, la discusión sobre la postmodernidad permitió, por ejemplo, comprender que el método etnográfico, en la medida en que siempre es resultado de interacciones entre investigadores e investigados, posee una naturaleza performativa. Consecuentemente, aquello «que extraemos de la investigación como 'datos' o 'información' algunas veces es encontrado, y muy a menudo es creado», [razón por la que] «nuestros materiales no son simplemente la molienda para molinos analíticos». (Fabian 2009: 363)

2 Recuérdese que para Radcliffe-Brown la antropología debía convertirse en una suerte de sociología especializada en «la comparación sistemática de sociedades de tipos diferentes, con atención especial a las formas -más simples- de la sociedad de los pueblos primitivos, salvajes o prealfabetos» (Radcliffe-Brown 1975: 149). Esta visión contrastaba mucho con la que pocos ańos después planteara Karl R. Popper: «en tanto que antes de la Segunda Guerra Mundial la idea de la sociología aún era la de una ciencia social teorética general-comparable quizá a la física teorética- y la idea de la antropología era la de una sociología aplicada a sociedades muy especiales, es decir, a sociedades primitivas, esta relación se ha invertido actualmente de la manera más asombrosa. La antropología social o etnología se ha convertido en una ciencia social general; y parece que la sociología se encuentra en vías de irse convirtiendo cada vez más en una rama de la antropología social, en una antropología social aplicada a una forma muy especial de la sociedad, en una antropología, en fin, de las formas de sociedad altamente industrializadas de Occidente. (...) La antropología social ha avanzado hasta convertirse en una ciencia especial aplicada a una ciencia básica y el antropólogo ha pasado a convertirse de en un modesto y algo miope fieldworker en un teórico social de vastas miras y hondo aliento, así como en un psicólogo social profundo.» (Popper 1972: 105-6) 
Del mismo modo, el énfasis que los seguidores de Geertz hicieron sobre los procesos hermenéuticos y la necesidad de la interpretación, «nos puso en alerta sobre el positivismo naif -ingenuo-, concerniente con las relaciones entre investigación y escritura en la producción del conocimiento etnográfico» (ibíd.). Ahora bien, esta constatación nos "hizo más científicos en tanto que agudizó nuestro conocimiento sobre la significancia epistemológica sobre la presentación y la representación» (ibíd.).

La profundización en la ciencia, desde este punto de vista, es justamente lo que ha permitido a los profesionales de la antropología alejarse tanto del positivismo como de diferentes formas de cientificismo que, so pretexto de la neutralidad, impide la interpretación de cualquier dato dentro del contexto en que fue producido. A la vez, como consecuencia de esta actitud, la antropología ha podido constatar en innumerables ocasiones cómo en momentos en que neutralidad axiológica, epistemológica y metodológica parecen confundirse, la vindicación de una supuesta objetividad o neutralidad -aunque ambas actitudes no sean idénticas- respecto de cualquier ámbito de lo social, conduce irremisiblemente hacia el mantenimiento de un status quo asentado en la desigualdad. Por tal motivo, asumimos que una serie de preconcepciones son inevitables independientemente de qué modelo explicativo estamos utilizando. Algo, por lo demás, común al conjunto de las ciencias sociales, ya que

el ámbito objetual de las ciencias sociales está ya constituido precientíficamente; en todo caso, el científico social al deslindar categorialmente su ámbito objetual, tiene que tener en cuenta que está tratando de distinguir una clase de objetos posibles que por su parte reflejan ya una estructura categorial, a saber: la estructura de ese saber preteórico con cuya ayuda los sujetos capaces de lenguaje y acción pueden generar tales objetos. (Habermas 1988: 459)

Es decir, las interpretaciones y análisis que hacemos están siempre en función de la selección previa de los hechos que consideramos significativos, frente a otros que, para nuestros propósitos, consideramos menos relevantes. Ciertamente ocurre a veces, y es usual entre quienes se inician en la disciplina, que durante el trabajo de campo no sepa de antemano que va a ser relevante y se procure recogerlo todo como consecuencia de «la actitud que tiene como lema 'en caso de duda, recoge datos'.» (Barley 1993: 75) En todo caso, que consideremos como más relevantes unos hechos que otros no significa necesariamente que los procesos de producción de conocimiento sean arbitrarios porque, en realidad, lo 
que le otorga el significado a cualquier dato es su imbricación en un modelo o marco teórico. Es decir, es el marco teórico en que ese dato es producido lo que da relevancia, esto es, significatividad, a cualquier hecho. En suma,

debemos admitir que el "cómo» de nuestra disciplina ya no está garantizado por la existencia de un «método científico» unificado. $\mathrm{O}$, si existe un método, éste no es concebible como uno ahistórico o apolítico. Y eso significa que los intereses hegemónicos, metropolitanos, ya no pueden esgrimir un instrumento que fue muy insidioso porque fue considerado como neutral y objetivo. La revolución epistemológica nos ha proveído espacios de libertad en los cuales nos podemos mover de manera innovativa, productiva e incluso amena - algo que, sin embargo, no debemos confundir con la seudo arbitrariedad liberal que va debajo del nombre posmodernismo. (Fabian 2009: 364)

Así pues, descartado que la antropología contemporánea deba circunscribirse a una mera búsqueda de ciertas regularidades empíricas, la cuestión es qué hacemos con la información que producimos una vez que somos capaces de hacer visible su significado. Porque, parece evidente, que, aunque del conocimiento antropológico no se derive directamente ningún «deber ser» concreto, la antropología no puede mantenerse aferrada al faro de la neutralidad. Máxime si se considera que «en ciencias sociales, lo participativo, frente a lo participante, se ha venido diferenciando por el cambio radical en la relación sujeto-objeto de la investigación» (Berraquero-Díaz et al. 2016: 52) y que, en determinados contextos, el antropólogo "participaba más que observaba, y se daba cuenta de que la implicación hacía retroalimentarse ambos polos, la observación y la participación» (Diz 2018: 135). Ciertamente, la antropología ha contribuido históricamente a la dominación. Pero, también, como indica Marilyn Strathern, «en el marco de un cometido crítico, también era parte de la formación antropológica aprender a criticar las categorías de análisis dadas (no había nada que no se prestase a un examen crítico)» (Corsín 2019). Gracias a ello, antropólogos y antropólogas, comprendiendo "cómo se forman estos relatos de coherencia en las diversas escalas articuladas de la acción y qué formas diversas del ser se alumbran» (Díaz de Rada 2008: 230), han podido ubicarse en una privilegiada posición que permite una adecuada vinculación entre teoría y práctica. Con ello, la antropología ha podido convertirse en «un agente crítico y transformador de la percepción de la complejidad de los procesos sociales, económicos, culturales y ambientales» (Tomé y Ferrándiz 2018: 292) en un "contexto de nuevas formas de dominación y extracción económica disfrazadas con lenguajes de diseño y mayor volatilidad de la experiencia» (Tomé y Ferrándiz 2019). 
De todos modos, ese proceso ha incluido el planteamiento y, a veces, superación de numerosos dilemas éticos (Del Olmo 2010) en el convencimiento de que la antropología que se limita a estudiar al hombre en su contexto social concreto para generar un conocimiento «desvinculado del compromiso ético de modificar y transformar la sociedad, no tiene sentido" (Nahmad 2008: 82). Por tanto, antropólogos y antropólogas, sobre todo cuando abordan situaciones dominadas por diferentes niveles de conflicto social, político o económico, deben involucrarse en su investigación de forma tal que, además de interpretar y visibilizar problemas sociales, se impliquen en su resolución. Es decir, superando controversias teóricas entre antropología aplicada o implicada, entre IAP y etnografías colaborativas, la indagación, sin confundirse con un activismo con el que mutuamente se retroalimenta, debe asumir como punto de partida firmes compromisos éticos previos al conocimiento antropológico. Aunque el precio que se pague sea la problematicidad de la posición de un etnógrafo que puede ser visto por una de las partes en conflicto como representante de la otra. En todo caso, quien se enfrenta a dicha situación, por mucho que pueda mantener su «certeza analítica», debe ser plenamente consciente de que, al perder la neutralidad, cabe la posibilidad de que «los sujetos» a los que investiga y con los que lo hace «se enturbien» generando «tipos especiales de problemas» (Ferrándiz 2008: 96). Ello incluye, por tanto, asumir que las situaciones de conflicto en que antropólogos y antropólogas se ven inmersos pueden conducir a contextos etnográficos novedosos impredecibles que, circunstancialmente, pueden exigir un «ajuste reflexivo y crítico de los métodos y objetos de estudio», como parte de la «realidad cada vez más compleja, global, interrelacionada y exigente con sus analistas» (Ferrándiz 2011 a: 84). Aún así, la forma de enfrentarse a estos contextos etnográficos novedosos ha de ser, como señalaba el citado Salomón Nahmad, «comprometer mi conciencia, mi ética y mis conocimientos con el objeto de mis estudios y de mi acción» (Nahmad 2008: 83).

Una ocasión para ver cómo solventar esa tensión entre la ecuanimidad que históricamente se exigió a las monografías etnográficas y el compromiso ético con nuestros interlocutores, nos llegó cuando Rights International Spain, un grupo de abogados que trabajan por la justicia internacional y los derechos humanos, nos solicitaron un peritaje antropológico. El mismo debía servir de apoyo a la demanda que contra el gobierno de Espańa iba a plantear Fausto Canales ante el Tribunal Europeo de Derechos Humanos con sede en Estrasburgo. 


\section{¿Quién es Fausto Canales y por qué pretendía pleitear contra el gobierno español?}

El 20 de agosto de 1936, un mes después del fallido golpe de estado del 18 de julio, un grupo de falangistas llegaron de madrugada a Pajares de Adaja, un pueblo de la Moraña abulense que tenía entonces cerca de 600 habitantes ${ }^{3}$. Allí seleccionaron a varias personas que habían sido marcadas previamente por algunos de sus convecinos. Esa noche los falangistas secuestraron a Celestino Puebla Molinero, Emilio Caro García, Pedro Ángel Sanz Martín, Román González Enrique, Víctor Blázquez del Oso y Valerico Canales Jorge. También a una mujer: Flora Labajos Labajos. A todos los sacaron a la fuerza de sus casas, los subieron a una camioneta y se los llevaron a un destino para ellos incierto. Por la carretera de Arévalo a Madrigal de las Altas Torres llegaron hasta Aldeaseaca, otro pueblo de la comarca del que dista unos 25 kilómetros. Allí, tras asesinarlos, lanzaron sus cuerpos a un pozo seco. No era, evidentemente, un acto aislado4, sino uno más de un terror organizado que durante cuatro decenios fue seguido de silencio. El último de los varones nombrados, Valerico Canales Jorge, contaba entonces con 29 años y tenía dos hijos: Victorio, de cuatro años, y Fausto que acababa de cumplir dos. Es este último, Fausto, que actualmente tiene 85, quien se decidió a pleitear en el Tribunal Europeo de Derechos Humanos contra España para dar fin a ese silencio oprobioso.

Fausto, como muchos otros, había creído que, tras la muerte del dictador, la llegada de la democracia y la constitución de 1978 satisfarían su sed de justicia.

\footnotetext{
3 Según el censo de 1930 Pajares, actualmente Pajares de Adaja, tenía 536 habitantes de hecho y 571 de derecho para un total de 139 hogares (Fuente: INE. Alteraciones de los municipios en los Censos de Población desde 1842).

4 Según Bruno Coca, presidente del Foro por la Memoria de Ávila, en La Moraña, comarca en que se encuentran tanto Pajares de Adaja como Aldeaseca, fueron asesinados el alcalde o parte de la corporación de pueblos como Mamblas, Barromán y Fontiveros, así como un indeterminado número de vecinos (en torno a 200) y, sobre todo, cuadrillas completas de «serranos» y "gallegos» que, como todos los veranos, habían llegado para emplearse en las llanuras cerealistas como segadores. (Comunicación personal). En 2015, la web \#15Mpedia. org, recogiendo las incluidas en el Mapa de Fosas del Ministerio sin actualizar desde 2011, indicaba que en la misma comarca se habían exhumado fosas en Aldeaseaca (2), Bercial de Zapardiel (2), El Bohodón y Las Berlanas. Además, documentaba otras en Arévalo, Flores de Ávila, Fuente el Sauz, Monsalupe, Moraleja de Matacabras, Sanchidrián y Villanueva del Aceral, así como una desaparecida en Adanero. (http://15mpedia.org/wiki/Lista_de_fosas_ en_la_provincia_de_\%C3\%81vila [Consulta de 12/08/2019]) En dicho listado no se incluye la exhumada en 2014 en la localidad de Chaherrero, en el municipio de Crespos, gracias a una ayuda económica del sindicato de electricistas noruego Elogit.
} 
Algo que debería iniciarse con la recuperación del cadáver de su padre desaparecido desde 1936. Sin embargo, por encima de sus deseos, un techo de silencio se mantenía inquebrantable haciendo que el tiempo pasara sin que la justicia asomara a su casa y compensara las penurias de una infancia en orfandad y una muerte sin explicar. Tanto tiempo pasó que a aquel niño que con dos años perdió a su padre, le llegó la edad del retiro profesional. Así pues, después de larga e infructuosa búsqueda, tras jubilarse en 1999, decidió dedicar todo su tiempo a averiguar qué le había ocurrido exactamente a su padre y dónde estaban sus restos. No contaba, o tal vez sí, con que en ese proceso de búsqueda debería topar una y otra vez con un inquebrantable mutismo que afectaba a todos los que debieran tener recuerdos: a pesar de la ayuda de la alcaldesa de Pajares de Adaja, nadie en su pueblo ni en el de Aldeaseca, cuyo alcalde también quiso ayudarlo, quería hablar. $\mathrm{O}$, tal vez, querían pero no podían. Nadie, entre los más mayores, parecía haber visto nada ni sabido nada. El miedo, con su secuela de silencio, seguía campando libre. Aunque todos sabían que todos sabían. De hecho Fausto tenía indicios razonables de quién había colaborado con los falangistas denunciando a su padre. De quién había proporcionado la cuerda con la que lo maniataron y de quién estaba en la puerta de su casa esperando la detención.

Finalmente, preguntando aquí y allá, con medias verdades e indicaciones no explícitas, encontraron la fosa a la que su padre y sus vecinos fueron arrojados después de un inhumano fusilamiento. En 2003, cuando ya los medios de comunicación comenzaban a hablar de forma no esporádica de exhumaciones e incluso ya se había producido una en la provincia de Ávila, concretamente en Candeleda, Fausto logró que se procediera a abrir la fosa de Aldeaseca a la que su padre fue arrojado. Lo que descubrieron entonces es que, aunque había algunos fragmentos de huesos humanos, ni los cuerpos de su padre ni los de los que con él murieron seguían allí. Era evidente que el lugar había sido saqueado en algún momento posterior al asesinato. El alcalde de Sinlabajos, una persona con prestigio en la comarca ${ }^{5}$, logró que de forma discreta alguien de Aldeaseca le contase que en 1959 el lugar había sido vaciado por representantes de la autoridad. Así pues, aunque allí hubiera algunos huesos la investigación hubo de continuar y, pensaba Fausto, si habían sido autoridades quienes habían vaciado la fosa, algún rastro documental debía haber. Efectivamente, logró dar con un documento en la subdelegación del gobierno que probaba que la fosa había sido abierta y los restos que en ella se encontraban habían sido sacados por una caravana que,

\footnotetext{
5 Goyo, como era conocido Gregorio García Antonio, fue alcalde de Sinlabajos desde 1979 hasta enero de 2008 cuando falleció en un acto público.
} 
de camino a Ávila, repitió lo mismo en otra fosa en Fuente el Sauz y en una de Flores de Ávila. Todas con cuerpos de simpatizantes republicanos asesinados en esas primeras fases del terror caliente ${ }^{6}$. Así pues, Fausto siguió con sus pesquisas hasta descubrir un hecho que, cuando se hizo público, llenó de estupefacción a miles de familiares de asesinados por el régimen franquista: en 1959, antes de la inauguración del gigantesco mausoleo levantado en Cuelgamuros, autoridades franquistas ordenaron que miles de personas muertas en la represión fueran trasladadas clandestinamente a la basílica del denominado Valle de los Caídos. Tal orden no perseguía una vana reconciliación o algo semejante. La excusa era más prosaica: había que «llenar» el cementerio que se iba a inaugurar y los muertos «propios» no eran suficientes tal cometido. Es decir, Fausto, cuando aún no era de dominio público como lo es ahora gracias a su acción, descubrió que posiblemente miles de asesinados por el régimen se encontraban enterrados junto a quien, en última instancia, propició tantos asesinatos en masa: víctimas y victimarios compartían tierra en una cruel ironía que lejos de ser apaciguadora añadía sufrimiento a los familiares de los desaparecidos.

A partir de ese momento Fausto no cejó en el intento de que le devolvieran los restos de su padre. Acudió a los juzgados que, como coloquialmente se dice, se fueron pasando la pelota de uno a otro: si el juzgado de El Escorial decía que no era competente para entender la cuestión, la Audiencia Nacional decía que debía ser uno territorial. Si pedía a Patrimonio Nacional que le devolvieran los restos de la caja 109 -en la que estaban los cuerpos exhumados de Aldeaseca, Fuente el Sauz y Flores de Ávila-, la respuesta era que ni en la caja ni en el libro de registro de entrada figuraba el nombre de Valerico. Ni el suyo ni el de más de las más de 12.000 personas que aparecen registradas bajo el epígrafe común de «anónimo». La tercera parte aproximadamente de los que allí fueron llevados. Finalmente, entre tanto vaivén, entre tanta frustración y enfado, entre tanta pena y rabia, la sala de lo penal del Tribunal Supremo dictó una sentencia en la que explícitamente afirmaba que:

6 El desactualizado «Mapa de fosas del Ministerio de Justicia» señala que la fosa 854/2009AVIL contaba con seis varones desconocidos que fueron trasladados al Valle de los Caídos el 23 de marzo de 1959 (http://mapadefosas.mjusticia.es/exovi_externo/CargarDetalleFosa.htm?fosaId=854 [Consulta del 12/08/2019]) En 1976 Daniel Sueiro (2006) calculó que podían haber sido trasladados a la abadía construida en Cuelgamuros los restos de unos 20.000 republicanos. Aunque se sabe que la cifra de los trasladados es mucho mayor, todavía hoy se desconoce exactamente cuántos y quiénes fueron. En todo caso, «la escala del traslado de cadáveres de la Guerra Civil hacia este monumento es sobrecogedora» (Ferrándiz 2009: 83). 
La búsqueda de la verdad es una pretensión tan legítima como necesaria. Corresponde al Estado a través de otros organismos y debe contar con el concurso de todas las disciplinas y profesiones, especialmente a los historiadores. Pero no corresponde al juez de instrucción, cuya función aparece definida en la ley procesal con un objeto de indagación que se va concretando en el devenir procesal y ve limitado su ejercicio por las normas que rigen el proceso penal y el derecho penal sustantivo. Es preciso un hecho con apariencia de delito y un posible imputado vivo. (TS. Sentencia $N^{\circ}$ : 101/2012)

Esta sentencia solamente tenía una relación indirecta con las peticiones de Fausto Canales pues el hecho juzgado en la misma era si el juez Baltasar Garzón, quien había sido inhabilitado y expulsado de la carrera judicial por un tema diferente en los días previos a que esta sentencia fuera dictada ${ }^{7}$, había cometido un delito de prevaricación al intentar investigar los crímenes del franquismo. Aunque la sentencia fue absolutoria, el Tribunal Supremo cerraba definitivamente cualquier investigación pues aseguraba, en el primero de los fundamentos de derecho en que se basaba que, si bien la pretensión de las «asociaciones para la recuperación de la memoria histórica de varios territorios» es «legítima en su demanda» de "conocer la verdad de los hechos acaecidos, el lugar de fallecimiento y de su enterramiento, y solicitan la tutela judicial para la exhumación e identificación de los cadáveres y así poder honrarlos y homenajearlos», "no podía ser atendida en su integridad». La razón que el Supremo alude para ello es que no es posible

una indagación judicial sobre unos hechos, con apariencia de delictivos, respecto a los que se sabe que no es posible que el proceso concluya con la declaración de culpabilidad de una persona, al concurrir una causa de extinción de la responsabilidad penal, muerte, prescripción o amnistía. (TS. Sentencia No: 101/2012)

Es decir, el Tribunal Supremo señalaba que no podía investigarse porque no se podría probar responsabilidad de nadie en los crímenes pues cualquier potencial victimario o habría muerto o estaría amnistiado o, directamente, habrían prescrito los delitos que hubiera cometido. En suma, aferrándose a la ley, la sala de lo penal del Supremo estableció que para las víctimas del franquismo no podrá

7 Se trataba de las escuchas del denominado caso Gürtel que investigaba la presunta corrupción del Partido Popular. El motivo de la inhabilitación fue que Garzón intervino las comunicaciones entre los acusados y sus abogados, lo que el Tribunal Supremo consideró propio de sistemas totalitarios 
haber el menor atisbo de justicia o de reparación. Y eso afectaba a varias decenas de miles de personas, incluido Fausto Canales.

Este, lejos de abandonarse a la desolación, decidió acudir al Tribunal Europeo de Derechos Humanos y, con el concurso del citado RIS (Rights International Spain), demandar al Reino de España «por su responsabilidad internacional derivada de la violación continuada de su obligación de llevar a cabo una investigación efectiva de la desaparición» de su padre, Valerico Canales (RIS 2012: 2). Es decir, Fausto Canales se vio en la necesidad de convertir la búsqueda de su padre, así como la justicia y la reparación que su desaparición exigían, en una demanda contra un Estado. El mismo que, ignorando todas las recomendaciones internacionales en materia de derechos humanos, incluso aquellos tratados firmados y asumidos, se ha negado reiteradamente a crear «las vías y mecanismos efectivos para el acceso a la justicia de las víctimas» (RIS 2012: 5). Algo que, además, la Sentencia del Tribunal Supremo de febrero de 2012, reconocía nítidamente. Entre la esperanza y el escepticismo, pensaba Fausto que tal vez en el Tribunal Europeo de Derechos Humanos podría, por fin, tener la respuesta judicial que tantas veces se le había negado en España y, consecuentemente, una efectiva reparación.

Pues bien, para apoyar esa demanda, RIS y Fausto Canales, que ya había asistido a varias sesiones del «Seminario de Rastros y Rostros de la violencia» que Francisco Ferrándiz organiza mensualmente en el CSIC (http://politicasdelamemoria.org/actividades/seminario-rostros-y-rastros-de-la-violencia/) y que, además, había sido protagonista directo o indirecto de alguno de los escritos publicados por el propio Ferrándiz (2011b, 2014) nos solicitó algún documento de apoyo. Es así, como surge el «Informe pericial sobre víctimas del franquismo en la sociedad española contemporánea» que conjuntamente firmamos el citado Francisco Ferrándiz, Julián López, María García, Pedro Tomé y Juan Antonio Flores. Pues bien, conscientes, como en 2015 dirá la EASA (European Association of Social Anthropologists) de que la antropología proporciona a sus practicantes habilidades y conocimientos que les permiten abordar cuestiones complejas, afrontamos la tarea de realizar el primer informe pericial antropológico que sobre las víctimas del franquismo se hace en España y que se fechó en Madrid el 15 de septiembre de $2012^{8}$.

8 Este peritaje de encuentra reproducido a continuación de este artículo. 


\section{Algunos condicionantes del peritaje}

Si bien la realización de peritajes por parte de antropólogos y antropólogas puede presentarse como algo novedoso, lo cierto es que se conecta directamente con los inicios de la disciplina: «los primeros grandes etnólogos modernos fueron juristas en su mayoría: Bachofen, Maine, McLennan, Morgan. Sin ellos resulta imposible comprender tanto el resurgimiento de la etnología, como los temas predilectos de los etnólogos del siglo XIX y la antropología social del XX (familia, parentesco, herencia, propiedad, etcétera)» (Palerm 1976: 160). Es más, en buena medida, el origen de la antropología contemporánea tiene que ver con el interés por el derecho comparado y la posibilidad de su aplicación, como resultó notorio tanto en el caso de Ancient Law, la obra de Maine, como sobre todo en las actividades que como jurisconsulto tuvo Morgan'. Desde entonces, aunque aún escasos en España, los peritajes antropológicos son relativamente frecuentes en la antropología. Particularmente los muchos que se realizan en América Latina, sobre cuestiones relacionadas con los pueblos originarios (Rodríguez Soto 2017; Loperena et al. 2018) u otros ámbitos de conflicto como los feminicidios (Lachenal et al. 2016). No obstante, hay que señalar que el monográfico que la revista Desacatos, publicada por el CIESAS, dedicó en 2018 a los «Dilemas del peritaje», arrancaba con la constatación de que el incremento de los mismos no ha ido seguido de "textos en los que se haya reflexionado de manera crítica sobre las rutas metodológicas y los dilemas éticos, políticos y epistemológicos» que plantean (Loperena et al. 2018: 8).

En cualquier caso, desde un punto de vista práctico, realizar un informe pericial antropológico sobre las víctimas del franquismo, suponíamos, no debía ser una tarea ímproba. Simplemente teníamos que ponernos de acuerdo en qué

\footnotetext{
9 Morgan pudo desarrollar gran parte de sus investigaciones gracias al éxito que había tenido como abogado de los grupos indígenas: «A certain land company had secured pre-emptive rights to purchase the lands of the Indian reservations in New York whenever the Indians should be willing to sell, and a treaty confirming this agreement was before the United States Senate for ratification. The disastrous effect on the future of the tribes of the establishment of this claim was realized by the society, and, with a view of defeating the measure, Morgan was sent to Washington, where he met with entire success in his mission. He thus became widely known and exceedingly popular among the tribes, and on October 1, 1847, was adopted into the Hawk clan of the Seneca nation as the Son of Jimmy Johnson, So-se-ba-wa, receiving the name of Taya-da-o-wub-kub, or One Lying Across - that is, a bridge or bond of union between the Indians and the white men. He now found himself admitted to the innermost circles of native society, and, once there, he embraced every opportunity to pursue his investigations.» (Holmes 1908:222)
} 
decir, cómo decirlo y razonar nuestras palabras. O sea, algo relativamente sencillo pues consistía, más o menos, en hacer lo que siempre hacemos: una investigación y su correspondiente justificación. Sin embargo, pronto descubrimos que no era tarea tan cómoda. Entre otras cosas porque el qué, es decir el contenido de lo que debíamos expresar en nuestro escrito, estaba condicionado de antemano por el para qué, por el objetivo que perseguía. Este, como pronto nos percatamos estaba, a su vez, coartado por los destinatarios de nuestro escrito.

Los antropólogos estamos acostumbrados a escribir nuestras monografías o artículos sin tener claro quién las va a leer. Entendemos, o damos por supuesto al menos, que en la mayoría de las ocasiones, nuestros escasos lectores son nuestros pares. Es decir, colegas que tienen un interés explícito por el tema que estamos investigando, por los avances de la disciplina o simple curiosidad. A veces, nuestros lectores son personas que sin interés alguno por la antropología pueden verse concernidas por la investigación. Por ejemplo, los vecinos de un determinado lugar sobre el que la monografía dice algo. También puede ocurrir que sean colegas de otras disciplinas que, por proximidad ideológica, teórica o temática, mantienen un interés por lo que podamos plantear. $U$ otros que han sido parte de una etnografía colaborativa. De una u otra forma, en unos y otros casos, escribimos para colectivos relativamente identificables y simultáneamente dotados de un cierto grado de anonimidad. Salvo cuando enviamos un artículo a una revista y escribimos pensando de manera específica en sus revisores o redactamos una tesis pensando en el tribunal, cosas que a veces ocurren, lo usual es que no escribamos pensando en lectores concretos, sino en un público indeterminado con el que luego podremos mantener algún tipo de diálogo sobre el contenido o la forma. Un diálogo, en todo caso, diferido. Escribimos ahora y dentro de un tiempo, a veces cuando mucho tiempo después un lector se topa con algo que ya hemos olvidado que habíamos escrito, podremos discutir sobre el contenido. Por eso nuestros textos habitualmente se acomodan a los usos académicos o escolásticos y con excesiva frecuencia constan de una presentación con los objetivos, la enumeración de las hipótesis, el desarrollo de la metodología empleada, los datos de la etnografía y unas conclusiones finales luego de explicar cómo se ha llegado a ellas con la investigación.

Pero este no era el caso que nos desafiaba. Debíamos presentar un informe pensando en unos lectores predeterminados que, antes de comenzar la narración, ya sabíamos quiénes serían. Nuestra obligación era plantear un texto cuyos específicos destinatarios iban a ser unos jueces especializados en derechos humanos. Esto es, unos lectores de cuya ecuanimidad no teníamos ninguna duda pero que 
podrían no tener ningún tipo de interés por nuestra disciplina o incluso ignorar su existencia. No obstante, nuestra esperanza era que la lectura de dicho escrito, junto con otra serie de consideraciones que no es necesario explicitar aquí, pudiera contribuir a que la decisión que debían tomar en el caso de Fausto Canales y que potencialmente podría afectar a los miles de personas que se encuentran en la misma disposición se inclinara en una dirección muy determinada. Pero, al intentar que unos jueces se vieran impelidos a tomar una decisión en una dirección determinada, el componente fundamental del texto no podía ser la exposición más o menos neutra de los resultados de una investigación o de la yuxtaposición de varias, sino la deliberada persuasión. Por tanto, acudiendo a los clásicos de la antropología, nos encontrábamos asumiendo, quién sabe si a nuestro pesar, la tesis que Malinowski planteó en «El problema del significado en las lenguas primitivas», según la cual el lenguaje «es un modo de acción, no un instrumento de reflexión» (Malinowski 1984: 327). ${ }^{10}$ Esto debería llevarnos, por tanto, a formular nuestro escrito recurriendo más a enunciados performativos o perlocutivos, en la terminología de Austin, que a los meramente enunciativos a los que estamos acostumbrados. En suma, conocer los destinatarios de nuestros textos condicionó de modo absoluto el tipo de redacción que teníamos que emplear y, consecuentemente, toda nuestra narrativa. Y ello aceptando que pudiera ocurrir que, finalmente, los jueces no admitieran la demanda y, por tanto, decidieran no leerlo.

Pronto constatamos que, aunque el texto tuviera como destinatarios últimos un grupo de jueces, previamente debía superar el filtro de unos intermediarios necesarios que debían interpretarlo adecuadamente. Me refiero a los abogados que representarían a Fausto Canales ante el tribunal. Los mismos tendrían que encontrarse con un texto susceptible de ser utilizado en un procedimiento jurídico en beneficio del demandante de justicia al que representaban. O dicho de otro modo, antes de que llegara a los jueces el texto debía ser leído, comprendido

10 Por mor del rigor, hay que señalar que Malinowski (1984: 327) se refiere a unos específcos usos del lenguaje: «tenemos que comprender que el lenguaje originariamente, entre los pueblos primitivos, no civilizados, no fue nunca utilizado como un mero espejo de pensamiento reflejado. La manera en que ahora lo estoy usando, al escribir estas palabras, la manera en que el autor de un libro, o un papiro o una inscripción grabada en piedra, tiene de usarlo, es una función muy alambicada y derivada del lenguaje. En este caso, el lenguaje se transforma en un trozo condensado de reflexión, un registro de un hecho o pensamiento. En sus usos primitivos, el lenguaje funciona como vínculo en la actividad humana concertada, como una parte de la conducta humana. Es un modo de acción y no un instrumento de reflexión». 
y asumido como propio por unos profesionales del derecho que, como los jueces, podrían no estar familiarizados con la antropología. Y, de paso sea dicho, tampoco lo pretendían: no querían nuestro informe antropológico para incrementar su saber, aunque pudiera hacerlo, sino para usarlo en pro de un objetivo específico. En consecuencia, debíamos convertir nuestro texto en una herramienta susceptible de ser utilizada por alguien sin interés alguno por los intrincados vericuetos teóricos en que nuestra disciplina se enreda. Por lo tanto, lejos de que nuestros iniciales lectores se acomodasen a nuestra forma de escribir, cual es usual en cualquier monografía, fuimos nosotros quienes debimos de asumir sus exigencias narrativas. Con ello, las primeras personas que nos leyeron se convirtieron en inapelables jueces de una escritura que se veía condicionada por un genérico principio de «si no lo puedo usar, no me sirve y si no me sirve, ¿para qué lo escribes?».

Tan acostumbrados a una ciencia básica cuyos efectos, si los tiene, solamente se perciben en el medio o largo plazo, veíamos cada día cómo el principio se concretaba en cuestiones que obligaban a introducir continuos cambios en lo que escribíamos. Así ocurría en cada ocasión en que los abogados nos alertaban de nuestras continuas veleidades teóricas que, lejos de ser reconocidas como ejemplo de erudición, eran tomadas como molestias que podían desviar a los jueces del objetivo perseguido al cual debía subordinarse todo. Algo semejante a lo que ocurría con la genealogía de los conceptos a la que tan afectos somos: al juez no le interesa quién propuso un concepto, cómo ha sido criticado y en qué ha devenido tras múltiples discusiones teóricas. Tampoco la relación con las transformaciones epistemológicas y aún ontológicas que le han afectado. Todo eso, sin desconsiderar nuestro rigor conceptual era, sin embargo, irrelevante: si había que introducir un concepto, este debía aparecer desnudo, sin rodearse de artificios y sin nada que pudiera contribuir a que la explicación en que se incardina pudiera mostrarse confusa. Lo mismo, por supuesto, podía decirse de cualquier cita ilustrada que, acudiendo al argumento de autoridad, supuestamente refuerza lo que se quiere decir. En suma, debía obviarse cualquier atisbo de barroquismo perifrástico para hacer del texto un eficaz instrumento susceptible de ser utilizado por abogados en beneficio de una causa que consideramos justa.

Por otra parte, nuestro punto de partida no podía ser una etnografía que se realizara ex novo con ese objetivo. No podíamos, como ocurre con algunos peritajes que se han llevado a efecto para apoyar las demandas de algunos pueblos originarios por la propiedad de la tierra, diseñar una investigación que nos condujera de manera «natural» a mostrar la licitud de la vindicación de unos 
derechos conculcados. Carecíamos del tiempo suficiente para diseñar una investigación de esas características y más aún para poder llevarla a cabo. Es más, si queríamos llegar a tiempo de una demanda que incluyera nuestro pericial entre la documentación que los jueces europeos debían estudiar, precisábamos, como el poeta dijo, de ese tiempo que «otros dejan abandonado porque les sobra o ya no saben qué hacer con él». Una opción posible para solventar este inconveniente podría consistir en tomar fragmentos parciales de las investigaciones realizadas por cada uno de los firmantes del peritaje, con independencia de cuál fuera el fin que perseguían cuando se realizaron, y conjuntarlas de modo que se convirtieran en la herramienta requerida. Sin embargo, no ignorábamos que la adecuada realización de una tarea como la descrita posee implicaciones epistemológicas inmediatas. Al convertirnos, en primer lugar, en «auxiliares del aparato judicial o de una de sus partes» (Escalante 2018: 72) se provocaba un "desplazamiento» de las bases teóricas desde las que nuestras respectivas investigaciones se habían realizado y, en cierto modo, una quiebra con los presupuestos de los que partieron. Esto supondría, en segunda instancia, separar los datos que pudiéramos aportar de los contextos etnográficos en que habían sido producidos y que, en un sentido amplio, les otorgaban significación. Es decir, este camino nos conducía a una cierta «mística del dato» que presupone que este tiene un significado en sí mismo. Comprobado que posible y razonable no necesariamente coinciden, debíamos descartar esa vía y evitar que nuestro texto fuese bien una mezcla más o menos armónica de aspectos parciales de escritos previos, bien una suerte de ecléctica síntesis de ideas dispares. En suma, para que el texto "funcionara» era necesario que aquellos elementos que íbamos a articular compartieran una cierta ontología y las epistemologías que de ella se derivan. Así pues, debíamos producir un documento nuevo que incluyera más que escritos precedentes, reinterpretaciones de aspectos contenidos en ellos que permitieran transformar nuestra precedente «observación participante» en "participación acompañante» (Escalante 2018: 81).

\section{Informe pericial sobre víctimas del franquismo en la sociedad española contemporánea}

El informe que finalmente redactamos se inicia con una inapelable constatación: el paradero, identificación y entierro digno de miles de personas desaparecidas en acciones represivas de retaguardia durante la guerra y los ańos siguientes es un problema que sigue sin resolverse. Tales desapariciones habrían sido ocasionadas por parte del ejército sublevado y grupos paramilitares a él asociados y, en su mayoría, estaban vinculadas directamente con la «violencia 
horizontal» ejercida por civiles, vecinos de los municipios e incluso familiares, en un entorno de connivencia, delación y denuncia. La ausencia de solución a esta cuestión resulta particularmente oprobiosa cuando se considera que la dictadura concluyó tras la muerte de Franco y ya han pasado cuarenta y un ańos desde que se aprobó una constitución democrática cuyas iniciales palabras indican que se formula «deseando establecer la justicia». Esta falta de resolución generó en su día, y todavía hoy, consecuencias dramáticas en los entornos familiares de quienes sufrieron esa represión, manteniéndose, por tanto, las consecuencias sociales, familiares, psicológicas, políticas o económicas en los lugares en que ocurrieron. Por otra parte, las secuelas de esa represión se han alargado en el tiempo porque muchas de las familias que la sufrieron hubieron de soportar durante años humillaciones, encarcelamientos, expropiaciones, depuraciones, multas y, en definitiva, marginación social. Todo ello ha provocado en muchos lugares que se extienda un miedo insuperable con el consiguiente silencio. Todavía hoy en muchos pueblos de Espańa, y es particularmente notorio en muchos de la provincia de Ávila, las personas de más edad, particularmente quienes han vivido gran parte de su vida como vencidos o descendientes de vencidos, se niegan a hablar de estos temas. A lo sumo, son materia privada intrafamiliar que anuda con el miedo y el silencio sentimientos de culpa y vergüenza y gran desconfianza institucional. En otros casos, miedo y silencio se han alargado tanto que no resulta extraño que muchas personas vengan a conocer sufrimientos padecidos por sus padres, abuelos u otros familiares, por personas ajenas a la propia familia pues nunca en casa se ha hablado de los mismos. Por ello, en el informe, las exhumaciones habidas en el siglo XXI, realizadas la mayor parte de ellas por la sociedad civil, se usan como indicadores de la persistencia en el tiempo de las políticas y culturas del miedo instaladas en la sociedad española durante la Guerra Civil y la dictadura. En ese sentido, como antropólogos sociales nuestro informe atestigua cómo hoy día las secuelas traumáticas de la Guerra Civil y el franquismo entre los derrotados y algunos de sus descendientes son todavía claramente perceptibles. Particularmente en un medio rural en que los descendientes de las víctimas y las de los victimarios llevan años conviviendo y deben seguir haciéndolo.

Estos efectos de largo plazo explicaban, en nuestra opinión, que ese silencio se hubiera convertido en una aparente inacción. Ante la pregunta explícita de por qué se reclama ahora y no a la muerte de Franco o en los ańos siguientes a la aprobación de la Constitución, el temor, recelo y dificultad para expresar públicamente los hechos acaecidos y sus consecuencias, llevan a sugerir que no se reclama cuando se quiere, si no cuando se puede. Y hasta ahora no se había podido. De hecho, hasta el año 2000, apenas existía una articulación de 
la sociedad civil a través de organizaciones no gubernamentales o asociaciones que pudieran trasladar a los afectados cómo operar o simplemente informarse. La ausencia de un tejido asociativo que, respecto a las personas desaparecidas y ejecutadas en la Guerra Civil y la dictadura, proveyera de apoyo de las víctimas del franquismo, es, a nuestro entender, un indicador de las dificultades que este colectivo ha tenido para dotarse de una cierta legitimidad social. La ausencia de esta legitimidad habría sido reforzada durante las últimas décadas por las instituciones del Estado que reiteradamente se han negado a ofrecer el mínimo amparo a las víctimas, de forma que cualquier solicitud del mismo, se ha traducido en sistemática frustración. Ello explicaría, igualmente, la extensión de una desconfianza sostenida hacia las instituciones del Estado. Máxime cuando responsables políticos de alto nivel han utilizado estas fundadas peticiones para generar controversias sociales. La falsa idea de que «se quieren reabrir heridas», reiterada en demasía por algunos irresponsables políticos, que conlleva la implícita acusación a las víctimas de pretender romper la convivencia democrática y lanzarnos nuevamente a una guerra civil, ha sido igualmente un inhibidor de la voluntad de muchas personas y colectivos para emprender acciones destinadas a conocer el paradero de sus familiares, rescatarlos de fosas comunes y solicitar esquemas institucionales de justicia y reparación a quien debía corresponder: el Estado español. En suma, nuestro informe, constataba que el alto nivel de represión de retaguardia sirvió como base de una pedagogía de la sangre asentada en la gestión del miedo de los derrotados que se concretó en un tratamiento diferencial de las personas ejecutadas en las retaguardias. Mientras se facilitaron exhumaciones y reinhumaciones de los cuerpos reclamados como propios por los vencedores, frecuentemente homenajeados y reconocidos, se abandonaros a su suerte a los cadáveres de los vencidos durante décadas.

Por otra parte, desde 1959 y hasta 1983 hubo un importante movimiento de cadáveres provenientes de fosas comunes y cementerios de la Guerra Civil de diverso tipo, hacia las criptas del principal monumento funerario del franquismo: el Valle de los Caídos. En total, según las cifras actualmente disponibles, se trasladaron 33.847 cuerpos a este mausoleo de los que una parte indeterminada de ellos provenían de fosas comunes republicanas, vaciadas y trasladadas sin conocimiento ni permiso de sus familiares.

Pero, además, resulta crucial entender las transformaciones sociales y políticas como procesos que afectan de manera diferencial a los distintos colectivos. Las percepciones sociales sobre la eficacia de los procesos y las transformaciones son también variables, y cambian de manera sustancial de generación a generación. 
Durante la transición española los agentes políticos optaron por un modelo de reconciliación que incluía una Ley de Amnistía y una ética de «echar al olvido» de manera consciente los crímenes del pasado. Esta actitud respecto al pasado traumático, el consciente "olvido activo» de los crímenes del pasado, en aras de una reconciliación nacional hizo que, de manera general, no se dieran las condiciones de posibilidad para que los familiares de los desaparecidos promovieran acciones públicas o privadas de investigación sobre las causas de las desapariciones y fusilamientos ni de reparación o dignificación de sus deudos. Máxime cuando durante décadas se han visto inmersos en un miedo ambiente que les ha marcado profundamente.

La proliferación e impacto mediático de las exhumaciones del siglo XXI, junto con el desarrollo de algunas políticas públicas de memoria, han modificado las condiciones de posibilidad y de legitimidad pública para que ahora familiares de las víctimas puedan actuar de forma diferente. En concreto, la publicidad de dichas exhumaciones y la aparición de tales políticas están iniciando una quiebra de la desconfianza y el miedo todavía instalados profundamente en determinados ámbitos de la sociedad espańola, especialmente en los ámbitos rurales que sufrieron la represión y en las personas socializadas durante el franquismo en un entorno de castigo de sus ideas políticas. A pesar de ello, las controversias y problemas generados en este proceso siguen actuando como inhibidores de la movilización de muchos familiares de víctimas que siguen contemplando cómo se deslegitima su sufrimiento y se criminaliza la posición de sus familiares en la contienda. La propia «Ley de memoria histórica» (Ley 52/2007) que habilita política y jurídicamente estas iniciativas, hace que el Estado se desentienda de la coordinación de proceso de investigación, rescate e identificación de las víctimas. Esto ha dificultado o imposibilitado la realización de numerosos proyectos. A ello hay que añadir las trabas burocráticas y administrativas, la dificultad de acceso a archivos, la llegada muy tardía e incompleta de protocolos técnicos de garantías, y las duras impugnaciones políticas y mediáticas que ha acompañado a todos los actos relativos a la búsqueda y localización de personas desaparecidas.

Por todo ello, el informe pericial concluye que el caso español tiene una especial relevancia desde el punto de vista del análisis comparado de la pervivencia del trauma social a través de generaciones. También pone de manifiesto las limitaciones a medio y largo plazo de los pactos políticos de élite -y las políticas de reconciliación asociadas a los mismos-, para resolver satisfactoriamente algunos temas complejos del pasado, así como para efectuar transformaciones ciertas y profundas en determinados ámbitos de la realidad social. La aparición 
y desarrollo posterior de mecanismos internacionales de denuncia y persecución de la impunidad, así como la eclosión de la llamada «justicia transicional», contribuyen también a poner en perspectiva histórica algunas limitaciones del modelo de transición elegido tras la muerte de Francisco Franco. En concreto, tal modelo no sólo no ha sido capaz de enfrentar con éxito este cardinal asunto, si no que ha tenido repercusiones negativas, ya en el periodo democrático, sobre los colectivos de víctimas a los que se refiere este informe.

\section{Coda: habla Estrasburgo}

El 15 de noviembre de 2012, en una escueta carta a los representantes legales de Fausto Canales se les comunicaba que, con fecha de 8 de noviembre, "una formación de juez único del Tribunal Europeo de Derechos Humanos (L.-A. Sicilianos asistido por un relator de acuerdo con el artículo 24.2 del Convenio) ha decidido inadmitir su demanda». La razón para esta inadmisión, «definitiva y [que] no puede ser objeto de recurso alguno ante este Tribunal, ante la gran Sala ni ante otro órgano», es que la demanda «no cumple con los requisitos de admisibilidad establecidos ${ }^{11}$. Es decir, el Tribunal Europeo de Derechos Humanos, sin entrar a valorar o discutir el contenido de la demanda, se remitía a unos criterios de admisibilidad establecidos en el caso de la inadmisión de la que presentaron en 2009 contra el gobierno de España la hija y el nieto de Luis Dorado Luque, diputado socialista fusilado en Córdoba en $1936^{12}$. En este caso, que no entró a juzgar lo acontecido en España y remitía sus decisiones a otras previos relacionadas con otros conflictos, principalmente de Turquía y del Este de Europa, se indicaba que aun siendo cierta la dificultad que los demandantes habían tenido para acudir ante tribunales nacionales,

no pueden esperar indefinidamente antes de interponer una demanda. De hecho, con el lapso de tiempo, los recuerdos de testigos se desvanecen, los testigos pueden morir o convertirse imposible de rastrear, la evidencia se

\footnotetext{
11 Esta comunicación, como toda la documentación del caso, están disponibles en la página web de RIS: http://www.rightsinternationalspain.org/ [Consulta realizada el 12/08/2019] En concreto, la carta puede consultarse en línea en

http://www.rightsinternationalspain.org/uploads/noticia/dbce14443525f3cd005baccfedeb4fffb57b8944.pdf

12 Gutiérrez Dorado y Gutiérrez contra Espańa. Demanda no 30141/09. La sentencia está disponible en línea en http://www.todoslosnombres.org/sites/default/files/documento561_0. pdf [Consulta realizada el 12/08/2019]
} 
deteriora o deja de existir, y las perspectivas de que cualquier investigación efectiva que pueda llevarse a cabo disminuirá cada vez más; y el propio examen y sentencia del Tribunal puede verse privado de significado y efectividad. (TEDH. Decision Application no. 30141/09)

A mayores, este cierre en falso del problema -pues adoptando una posición en exceso formalista, se impide de facto la consecución de justicia para las víctimas del franquismo-, añadía en el caso de Luis Dorado algo dramático. Tomando como ejemplo lo acontecido con desaparecidos en Chipre, se aseveraba que las demandas e investigaciones no están basadas en «ninguna esperanza realista de progreso en la búsqueda de cuerpos (...) ni posibilidad realista, de progreso en las medidas de investigación en relación con la desaparición de sus familiares».

Al no entrar el Tribunal a valorar ni la demanda de Fausto Canales ni la documentación que la acompañaba, se negó la posibilidad de discutir las razones que habíamos esgrimido para justificar la dilación en el tiempo de su presentación. Frente a la posición del Tribunal en el sentido de que no se puede esperar indefinidamente para acudir a la justicia, nuestro informe mostraba cómo a los tribunales se acude cuando se dan condiciones para ello; no cuando se quiere o se necesita. Y, hasta ese momento, no se habían dado. Pero, además, aunque el TEDH reafirmaba en el caso de Luis Dorado la obligación que los Estados tienen de investigar de forma efectiva las desapariciones, lo que entraría en contradicción con la idea del Tribunal Supremo español de que investigar los crímenes del franquismo rompe con la legalidad, materialmente se le daba la razón pues asume la idea de que «el derecho a conocer la verdad histórica no forma parte del proceso penal».

Nuestro peritaje no tuvo, por tanto, el efecto que buscábamos. Sin embargo, muestra claramente las posibilidades de una antropología comprometida con las víctimas. A la vez, huyendo de cualquier teorización y buscando únicamente la presentación ordenada de una serie de argumentos fruto de investigaciones precedentes, formaliza, de forma paradójica, una teoría relativamente completa y contrastada tanto en sus elementos particulares como de modo general, de los efectos de la inversión en el terror realizada durante la Guerra Civil y su larga postguerra. 


\section{Referencias bibliográficas citadas}

Barley, Nigel (1983). El antropólogo inocente, Barcelona: Anagrama. 5a ed.

Berraquero-Díaz, Luis, Francisco Maya-Rodríguez y Francisco J. Escalera Reyes (2016). «La colaboración como condición: la etnografía participativa como oportunidad para la acción», en Revista de Dialectología y Tradiciones Populares, 71-1: 49-57. Doi: https://10.3989/rdtp.2016.01.001.04

Bourdieu, Pierre, Jean Claude Chamboredon y Jean Claude Passeron (2002 [orig. 1973]). El oficio del sociólogo, Buenos Aires: Siglo XXI.

Corsín, Alberto (2019). «En relación: una entrevista con Marilyn Strathern», en Disparidades. Revista de Antropología, 74 (1), e003. Doi: http://dx.doi.org/10.3989/ dra.2019.01.003

Del Olmo, Margarita (ed.) (2010). Dilemas éticos en antropología. Las entretelas del trabajo de campo etnográfico, Madrid: Trotta.

DíAz DE RADA, Ángel (2008). «¿Dónde está la frontera? Prejuicios de campo y problemas de escala en la estructuración étnica en Sápmi», en Revista de Dialectología y Tradiciones Populares, 63-1: 187-235. Disponible en http://dra.revistas.csic.es/ index.php/dra/article/view/52/53

Diz, Carlos (2018). "Tácticas del cuerpo: activismo y resistencia en la ciudad en crisis», en Revista de Dialectología y Tradiciones Populares, 73-1: 127-152. Doi: https://doi. org/10.3989/rdtp.2018.01.005

EASA (2015). ¿Por qué es importante la antropología?. Disponible en http://www. easaonline.org/downloads/publications/policy/EASA\%20policy\%20paper_ES.pdf

Escalante, Yuri (2018). «Usos y costumbres del peritaje antropológico», en Desacatos 57: 72-81. Doi: https://doi.org/10.29340/57.1951

FABIAN, Johannes (2009). "Antropologías del mundo": interrogantes», en Ribeiro, Gustavo Lins y Arturo Escobar (eds.). Antropologías del mundo. Transformaciones disciplinarias dentro de sistemas de poder, México: The Wenner-Gren-CIESASUAM-Universidad Iberoamericana-Envión.

FERrÁndiz, Francisco (2008). «La etnografía como campo de minas: De las violencias cotidianas a los paisajes posbélicos», en Bullen, Margaret y Carmen Díez-Mintegui (coords.). Retos teóricos y nuevas prácticas, San Sebastián: Ankulegi: 89-116.

FERrándiz, Francisco (2009). «Fosas comunes, paisajes del terror», en Revista de Dialectología y Tradiciones Populares, 74-1: 61-94. Doi: https://10.3989/rdtp.2009.029

ÉNDOXA: Series Filosóficas, n. 44, 2019, pp. 47 -70. UNED, Madrid 
Ferrándiz, Francisco (2011a). Etnografías contemporáneas. Anclajes, métodos y claves para el futuro, Barcelona-México: Anthropos-UAM-Iztapalapa.

Ferrándiz, Francisco (2011b). «Guerras sin fin: guía para descifrar el Valle de los Caídos en la España contemporánea», en Política y Sociedad, 48-3: 481-500. Doi: https://doi.org/10.5209/rev_POSO.2011.v48.n3.36425

FERrándiz, Francisco (2014). El pasado bajo tierra. Exhumaciones contemporáneas de la guerra civil, Barcelona: Anthropos.

FrANCESCHI, Zelda A. (2019). «Emociones y significados en la autobiografía: Reflexiones a partir de un caso wichí (Gran Chaco)». Disparidades. Revista de Antropología, 74 (1), e002e. Doi: http://dx.doi.org/10.3989/dra.2019.01.002.05

Habermas, Jürgen (1988). "Un fragmento (1977): el objetivismo en las ciencias sociales”, en La lógica de las ciencias sociales, Madrid: Tecnos: 453-506.

Holmes, William H. (1908). «Biographical Memoir of Lewis Henry Morgan, 18181881. Read before the National Academy of Sciences, November 20, 1907", en Biographical Memoirs of the National Academy of Sciences of the United States of America, Washington D.C.: Press of Judd \& Detweiler, Inc.: 219-239. Disponible en línea en: http://www.nasonline.org/publications/biographical-memoirs/memoir-pdfs/morgan-lewis.pdf

Lachenal, Cécile et al. (2016). Guía metodológica para la elaboración de peritajes antropológicos, psicosociales y socioculturales en casos de feminicidios en México, México: Católicas por el derecho a decidir. Disponible en https://www. observatoriofeminicidiomexico.org/copia-de-informes-ocnf-medidas-de-p

Loperena, Christopher, Rosalva Aída Hernández Castillo y Mariana Mora (2018). «Los retos del peritaje cultural. El antropólogo como perito en la defensa de los derechos indígenas», en Desacatos 57: 8-19. Doi: https://doi.org/10.29340/57.1947

LowIE, Robert H. (1960 [1936]). "Cultural Anthropology: A Science», en DuBois, Cora (comp.). Lowie's Selected Papers in Anthropology, Berkeley: University of California Press. [Disponible en https://archive.org/details/lowiesselectedpa00lowi ]

Lowie, Robert. H. (1985 [1937]). Historia de la etnología, México: FCE. 3a Reimp.

Malinowski, Bronislaw (1984 [1964]). «El problema del significado en las lenguas primitivas», en Ogden, Charles K. e Ivor A. Richards. El significado del significado, Barcelona: Paidós: 310-352.

Nahmad, Salomón (2008). «Compromiso y subjetividad en la experiencia de un antropólogo mexicano", en Revista de Dialectología y Tradiciones Populares, 63-1: 75:119. Disponible en http://dra.revistas.csic.es/index.php/dra/article/view/48/49

Palerm, Ángel (1976). Historia de la etnología: los evolucionistas, México: CIS-INAH. 
Popper, Karl R. (1973 [1961]). «La lógica de las ciencias sociales», en Adorno, Th. W. et al. La disputa del positivismo en la sociología alemana, Barcelona: Grijalbo: 121-138.

RadCliffe-Brown, Alfred R. (1975 [1958]). El método de la antropología social, Barcelona: Anagrama.

RIS (Rights International Spain) (2012). Tribunal de Derechos Humanos. Demanda. Canales Bermejo c. España. No 56264/12. Disponible en http://www.rightsinternationalspain.org/es/litigios/2/tedh

Rodríguez Soto, Leila (2017). «El Uso del Peritaje Cultural-Antropológico como Prueba Judicial en América Latina: Reflexiones de un Taller Internacional», en Revista Uruguaya de Antropología y Etnografía, 2-1: 103-112). Disponible en: http:// www.scielo.edu.uy/pdf/ruae/v2n1/2393-6886-ruae-2-01-00103.pdf

Sueiro, Daniel (2006 [1976]). El Valle de los Caídos: Los secretos de la cripta franquista, Madrid: La Esfera de los Libros.

Tomé, Pedro y Francisco Ferrándiz (2018). «Mudar de nombre», en Revista de Dialectología y Tradiciones Populares, 73-2: 287-294. Doi: https://doi.org/10.3989/ rdtp.2018.02.001

Tomé, Pedro y Francisco Ferrándiz (2019). «Un mundo de disparidades», en Disparidades. Revista de Antropología, 74-1, e001. Doi: http://dx.doi.org/10.3989/ dra.2019.01.001

Tribunal Supremo. Sala de lo Penal (2012). Sentencia No 101/2012. Causa especial $N^{v}$ 20048/2009. Fallo/Acuerdo: Sentencia Absolutoria. Incluye un voto particular Procedencia: Juicio oral. Fecha de la sentencia: 27/02/2012. Ponente Excmo. Sr. D.: Andrés Martínez Arrieta Secretaría de Sala: Ilma. Sra. Dña. María Antonia Cao Barredo.

Tylor, Edward B. (1977 [1871]). Cultura Primitiva, Madrid: Ayuso.

Recibido: 18/09/2019

Aceptado: 21/11/2019

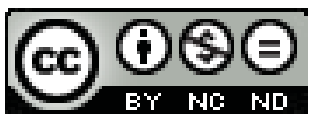

ENDOXA está bajo una licencia de Creative Commons Reconocimiento-NoComercial-SinObraDerivada 4.0 Internacional 